\title{
Dijital Ortamda (Ç)evrilen Toplum: Bulgaristan Göçmenlerinin Dijital Ortam Çeviri Pratiklerine Netnografik Bir Yaklaşım*
}

\section{Society Transformed and Translated in Digital Environment: A Netnographic Approach to Digital Media Translation Practices of Bulgarian Turks}

\author{
Burcu Kanıdinç ${ }^{1}$ (1)
}

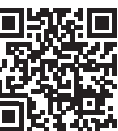

*Bu makale, 2018-2019 yılı güz döneminde Yıldız Teknik Üniversitesi, Diller ve Kültürlerarası Çeviribilim doktora programında, Prof. Dr. Emine Bogenç Demirel'in yürüttüğü MTF6119 Çeviri Sosyolojisi ve Dijital Ortam Çeviri Pratikleri adlı ders için hazırlanan ödevin genişletilmiş halidir. Saha çalışması çerçevesinde veriler Mart 2021 tarihinde yeniden gözden geçirilerek güncellenmiştir.

'Adana Alparslan Türkeş Bilim ve Teknoloji Üniversitesi, İnsan ve Toplum Bilimleri Fakültesi, Ingilizce Mütercim ve Tercümanlık Bölümü, Adana, Türkiye

ORCID: B.K. 0000-0001-5681-9101

Sorumlu yazar/Corresponding author: Burcu Kanıdinç (Arş. Gör.)

Adana Alparslan Türkeş Bilim ve Teknoloji Üniversitesi, Insan ve Toplum Bilimleri Fakültesi, Ingilizce Mütercim ve Tercümanlık Bölümü, Adana, Türkiye

E-mail: bkanidinc@atu.edu.tr

Başvuru/Submitted: 30.03 .2021

Revizyon talebi/Revision requested: 21.04.2021

Son revizyon/Last revision received: 28.04.2021

Kabul/Accepted: 30.04 .2021

öz

Yeni medya çalışmaları, geleneksel medya çalışmalarının aksine dijital mecrayı etkileşimsel ağlar örgütlenmesi olarak ele alır. Bu dijitallik kapsamında bilgi ve iletişim teknolojileriyle bağlantılı iletişim ve medya pratiklerini kapsar. Yeni medyada, katılımcının metni yeniden üretip yapılandırma rolü bulunduğundan katılımcılar arasında işbirliği mümkündür. Yeni medyanın en önemli iletişim araçlarından biri olan sosyal medya ağları, insanların ilişkiler kurduğu ve bağlantılarını hiçbir sınır olmaksızın uzaktan gerçekleştirdiği, seçici yakınlık eğilimlerini artırdığı araçlardır. Facebook gibi kişilerin anonim olmayan profilleriyle yakınsama kültürünün bir parçası olduğu dijital ortamlar, insanlara ortak bir kimlik oluşturma fırsatı verir. Çeviri pratiğinin yeni medyada aldığı konum da bahsedilen katılımcı paylaşımcı kültürün bir izdüşümüdür. Bu bağlamda, çalışmanın amacı, Bulgaristan göçmenlerinin, göçmen kimlikleriyle dijital ortamdaki çeviri pratiklerine dair çıkarımlarda bulunmaktır. Çalışmada Bulgaristan'dan Türkiye'ye göç eden göçmenlerin bir araya geldiği, en az iki ülke, dil, din ve kültürün dahil olduğu ve bu unsurların birbiri içinde akıcı bir şekilde dönüştüğü gözlemlenen bir Facebook grubuna odaklanıldı. Netnografik yöntemle, katılımcıların dijital ayak izlerine dayanarak, kültürel etkileşimleri ve aktarımları hakkında ham saha verilerine ulaşıldı. Belirtilen grubun dijital ortamdaki çeviri pratiklerine, Manuel Castells'in bahsettiği ağ toplumunda, Henry Jenkins tarafından ortaya atılan yakınsama kültürü ve katılımcı kültür kavramlarıyla yaklaşılarak netnografik bir çözümle sunmak amaçlandı.

Anahtar kelimeler: Ağ toplumu, yakınsama kültürü, katılımcı kültür, netnografi, dijital ortam çeviri pratikleri

\section{ABSTRACT}

In contrast to traditional media studies, new media studies examine digital media as an interactional network organization. It also includes communication and media practices associated with information and communication technologies. As the participant plays a role in reproducing and reconstructing the text in the new media, cooperation between the participants is enabled. Social media 
networks, one of the most important communication tools of new media, are platforms in which people establish relationships and carry out their connections remotely, without any limits, and where they are able to increase their selective affinity tendency. Digital environments, where a culture of convergence is formed by creating non-anonymous profiles of people like Facebook and creating an environment of mutual consensus, give people the opportunity to build a common identity. The position of translation practices in new media is also a projection of the participatory sharing culture. The aim of this study is to make inferences with netnographic analysis through the digital environment translation practices of Bulgarian Turks in a digital environment. The study focused on a Facebook group for Turkish migrants in Bulgaria. The group members are adept at navigating at least two countries, languages, religions, and cultures, and these elements transform fluidly within each other. The study yielded uninterpreted data about their cultural interactions and transfers based on the digital traces of the participants via a netnographic method. It also aimed to present the translation practices of the specified group in a digital environment with a netnographical analysis, with an examination of Henry Jenkin's convergence culture and participatory culture concepts in network society. Keywords: Network society, convergence culture, participatory culture, netnography, digital environment translation practices

\section{EXTENDED ABSTRACT}

Unlike traditional media tools, new media tools include social media networks, which use information and communication technologies and new socialities arising in these networks. The agents of new socialities are developing in a democratic, fast, and horizontal digital environment. Participatory and convergence culture (Jenkins, 2006a, 2006b and 2009) is indispensable in this environment. Because participants come together on a common platform to exchange information and establish connections in digital environments, they comprise a "convergence culture" (Jenkins, 2019) and create a collective intelligence, "making all relevant information available to [them] at any time" (Lévy, 1999, 217).

The new network-based socialities and democratization movement that came to the fore with the sociological turn in the field of translation (Bogenç-Demirel \& Süter-Görgüler, 2019; Bogenç-Demirel, Süter-Görgüler \& Kurmel, 2017; Bogenç-Demirel, 2014) reveal the importance of focusing on the digital media translation practices of actors in the field. Digital media translation practices, which are the reproducer of social-media-based movements, play a mediating role in the interaction and cultural exchange between new actors of new media. Due to the fact that convergence is also a "cultural change" (Jenkins, 2019, 20), we focused on the digital media translation practices of Bulgarian Turks who are adept at navigating at least two languages, countries, and cultures. Bulgarian Turks have arrived in Turkey in several waves of migration since the establishment of the Republic of Turkey until the present day (those with the character of mass migration movement occurred in four large waves until 1989). On the other hand, the Bulgarian Turks who migrated are struggling to protect and maintain their common cultural values. This desire has also been reflected in the digital environment with mutual interaction.

The aim of the study is to examine the reflections of the society, which is transformed and translated by the behaviors specific to the network society, on the digital environment in a 
closed group formed on the Facebook and to make inferences through digital media translation practices. The research questions developed in this direction are as follows: "Considering the posts shared in the group, how do the behaviors specific to the 'convergence culture' and 'participatory culture' exhibited by the community members in the network society, as the focal point of netnographic analysis, reflect on the digital environment?" and "How do agents in the network build digital media translation practices?"

The methodological approach of the study is netnography, "internet or network ethnography," which was introduced by Kozinets $(2010,1)$. Netnography, which makes it possible to reach the "natural," "uninterrupted data" set in the digital environment, is one of the "solid methods" that can be used to reach the cultural experiences of the researched community (Kozinets, 2010, 11-12). In this study, we tried to analyze the digital media translation practices of the Bulgarian Turks with respect to the concepts of "convergence culture," "participatory culture" (Jenkins, 2006a, 2006b and 2009), and "collective intelligence" Lévy (1999), in line with the netnographic methodological approach.

The findings of the netnographical analysis showed that participatory culture has led to a cycle in which each individual within the group struggles to exist and produce more content. The mission of carrying the network to a sustainable position is important for the agents to increase the group dynamics. The group is a multi-lingual, multi-layered, and active platform where translation practice takes place continuously, including at least one bilingual social network platform where both Turkish and Bulgarian language and culture are included in the circulation. It would not be wrong to claim that Bulgarian Turks, who are the subject and object of their own change and transformation with the change of living environment, language, and culture, use the translation practice as a reproduction tool in the relevant digital platform for the interaction and transformation of the digital environment. 


\section{Giriş}

Yeni medya, geleneksel metinden ve medyadan farklı olarak insanların aynı küresel ağ üzerinde, aynı sayfada, aynı anda, uzaktan iletişimlerini mümkün kılıp ağ üzerindeki çoklu yapıların ve kolektif zekânın uygulamaya geçmesini, başka bir deyişle kolektif üretimi doğurmuştur (Lévy, 1999; Jenkins, 2006'dan aktaran Binark, 2014, 23). Bu durum, ağa dâhil olan her bir katılımcının aynı zamanda üretici bir konuma gelerek katılımcı-paylaşımcı bir görev almasına hizmet eder ve bulundukları müdahalelerle her bir katılımcı ağ üzerinde aktif birer eyleyici olarak ağı şekillendirerek "yapılandırma” misyonunu da ellerinde bulundurmalarına imkan sağlar. Yapılandırma, paylaşımcıların "yazarsılokur" konumunda, "düzçizgisel olmayan” çevrimiçi dijital ortamda, "multimedya biçemselliğini”" (Binark, 2014, 21) işleyerek etkileşimsel dönüşümlerini yansıttıkları bir süreçtir. Çalışmaya konu olan paylaşımcıların birer göçmen olarak içinde bulundukları işleyişe müdahilliği de bu aşamada gerçekleşmektedir.

Çalışmanın amacı, Bulgaristan göçmenlerinin katılımcı-paylaşımcı eyleyiciler konumunda rol aldığı Facebook sosyal ağında oluşturdukları kapalı bir grupta, ağ toplumuna özgü davranışlarla (ç)evrilen toplumun, çevrimiçi/dijital ortama yansımalarını incelemek ve dijital ortam çeviri pratikleri aracılığıyla çıkarımlarda bulunmaktır. Sözü edilen pratikler, içinde her türlü "dijitallik, etkileşim, hipermetinselliklik, multimedya biçemselliği, kullanıcı türevli içerik üretimi, mevcudiyet hissi ve yayılımı” (Binark ve Löker, 2011'den akt. Binark, 2014, 20) barındıran "yorum” şeklinde genellenebilecek dijital ortam etkileşimleridir. Bu doğrultuda geliştirilen araştırma soruları ise, "A $\breve{g}$ toplumunda, üyelerin sergiledikleri “yakınsama kültürü” ve "katılımcı kültür”"e özgü davranışlar, çevrimiçi/dijital ortama nasıl yansımaktadır?” ve "ağ içerisindeki eyleyenler dijital ortam çeviri pratiklerini nasıl inşa etmektedir?” şeklindedir.

Makale Bulgaristan göçmenlerine dair art alan bilgisiyle devam etmektedir. Ardından bir sonraki bölümde etkileşim kavramı, Henry Jenkins'in “yakınsama kültürü” (2006a) ve "katılımcı kültür" (2006b ve 2009) ve Pierre Lévy’nin kolektif zeka (1999) kavramları üzerinden tartışılmakta ve etkileşimin gerçekleştiği çevrimiçi paylaşım platformunda konum alan aktörler arasındaki ilişkiler betimlenmektedir.

\section{Türkiye Cumhuriyeti Tarihinde Bulgaristan'dan Göç Dalgaları}

Bulgaristan'da yaşayan Türk etnik grup olarak tanımlanabilecek Bulgaristan Türkleri, çoğunlukla 14. ve 15. Yüzyılda Osmanlı Devleti’nin fethettiği Balkan topraklarında uyguladığ iskân politikasının bir sonucu olarak buralara yerleşen Türklerden oluşmaktadır (Stein, 2000, 238; Crampton, 1997, 36). Fakat Osmanlı Devleti'nin yıkılması ve içinde barındırdığı çeşitli etnik grupların dağılmasıyla birlikte, Bulgaristan Türkleri de Türkiye Cumhuriyeti'nin kuruluşundan itibaren günümüze dek farklı göç dalgalarıyla muhacir olarak ülkemize göçmüştür. 2011 yılında yapılan sayıma göre 588.318 Bulgar kökenli Türk, kabaca Türkiye Cumhuriyeti nüfusunun \%8,8'ini oluşturarak ülkenin en büyük etnik azınlığı sınıfına dâhil olmuştur ("Преброяване 2011” [Nüfus Sayımı 2011], 24.03.2021). Bulgaristan'dan gelen bu göçler, kitlesel göç hareketi 
niteliğine sahip olup 1989 yılına kadar dört büyük dalga şeklinde gerçekleşmiştir (Doğanay, 1996):

1925 yılındaki Türk - Bulgar ikamet sözleşmesi ile 1949 yılına kadar 218.998 kişi Türkiye'ye göç etmiştir.

1946 yılında Bulgaristan Halk Cumhuriyeti'nin ilanından sonra, 1949-1951 döneminde Bulgaristan'dan Türkiye'ye gelen toplam göçmen sayısı 156.063'tür.

1968 - 1979 yılları arasında da "Türkiye-Bulgaristan Yakın Akraba Göçü Anlaşması" çerçevesinde 116.521 kişi Türkiye'ye göç etmiştir.

Bulgaristan'dan son göç hareketi 1989 yılında Türk kökenli Müslüman Bulgar vatandaşlarının, Bulgar hükümeti tarafından Türkiye'ye göçe zorlanmaları ile başlatılmıştır ("Kitlesel Akınlar", 24.03.2021).

Yapılan bu göçler, özellikle zorunlu göçler, daha önce Bulgaristan'da yaşayan Türklerin bir benlik ve kimlik koruma mücadelesi olarak değerlendirilebilir. 1950-51 yıllarında gerçekleştirilen göçler Bulgaristan Hükümeti'nin Türkiye’ye nota vermesi sonucunda sınır kapılarının açılmasının ve ardından “Türkiye-Bulgaristan Yakın Akraba Göçü Anlaşması”nın imzalanmasının 1968-1979 göçünün yaşanmasına sebep olduğu bilinmektedir. Bu tarihlerden sonra Bulgaristan yönetimi tarafından Türkçe seçmeli derslere izin verilmemesi, Türkçe gazete ve dergilerin kapatılması, Bulgaristan Türklerinin etnik bir azınlık olarak görülmekten ziyade yok sayılma politikasına gidilmesi (zorunlu isim değişikliği, ibadet kısıtlaması vb.) gibi sert uygulamaların Türkiye'de basına sıklıkla yansıdığı görülmektedir. CNN Türk, “Asimilasyon ve Göç: Bulgaristan Türklerinin Öyküsü” başlıklı haberinde, bu süreci “Jivkov, isim değiştirme kampanyasına 'Soya Dönüş Süreci' adını vermişti. Osmanlı döneminde zorla Türkleştirilmiş olan Bulgarların, Bulgar isimlerini gönüllü olarak geri aldıklarını iddia etmekteydi” şeklinde açıklamaktadır (“Asimilasyon ve Göç: Bulgaristan Türkleri’nin Öyküsü”, 17.03.2021).

Kitlesel göç dalgaları elbette geride ailelerini, akrabalarını, dostlarını, komşularını bırakan muhacirlerin bir yanlarının hep geldikleri yerlerde kalmasına ve geldikleri yerlerle bağlantılarını devam ettirme konusunda hassasiyet göstermelerine sebep olmuştur. Türk nüfusunun yoğun olduğu bu bölgelerde yaşayan Türklerin, sıklıkla Bulgaristan' da daha önce yaşadıkları yerleri ziyaret ettikleri, oralara duydukları hasreti dindirebilmek ve oralardan haber alabilmek için mümkün olduğunca iletişimde kalmayı amaçladıkları bilinmektedir. Artık internetin hayatımızın bir parçası haline gelip sınırların ötesine ulaşabilmesi, Bulgaristan göçmenlerinin de dijital ortamda aktif birer katılımcı-paylaşımcı birey olarak konum almasına ve özgün kültürlerini olabildiğince canlı tutmaya çalışmalarına olanak sağlamıştır.

\section{Dijital Ortamda Yakınsama/Yakınlaşma Kültürü, Katılımcı Kültür ve Kolektif Zeka}

İletişim, Sinema Sanatları ve Eğitimi profesörü Henry Jenkins, Türkçeye "Cesur Yeni Medya: Teknolojiler ve Hayran Kültürü” şeklinde çevrilen kitabında okuyucusunu üç kavramla tanıştırır: "medya yakınlaşması, katılımcı kültür ve kolektif zeka" $(2019,19)$. Jenkins yakınlaşma ile çeşitli medya ortamlarında içeriğin akışını kast eder. Yakınlaşmanın, bu akışta kullanıcıların 
"beyinlerinde ve onların diğerleriyle sosyal etkileşimlerinde" meydana geldiğini iddia eder. Yakınlaşma, aynı zamanda "kültürel bir değişim”dir (Jenkins, 2019, 20). Katılımcıların kendi istekleriyle ortak bir paydada bir araya gelerek bilgi alışverişinde bulundukları ve bağlantılar kurdukları dijital ortamlar, kültürel yakınlaşmayı beraberinde getirerek “yakınsama kültürü”nü ortaya çıkarır (Jenkins, 2019). Dijital ortamdaki sosyal ağların oluşturduğu kendine özgü bu kültür (Castells, 2005, 497), geleneksel toplum yapısının değişip dönüştüğü, internet ağ tabanlı yeni toplumsallıkların oluşturduğu ağ toplumunun bir parçasıdır. Bu durumda, yakınsama kültürüne göre, rollerinin ve etkilerinin farklı derecelerine rağmen ağdaki üyelerin hepsi birer katılımcıdır ve bu katılım "açık uçludur" (Jenkins, 2019, 201). Bu eksende, katılımcılar kendilerine ters düşen veya ilgilerini çekmeyen ortamlardan dilediğinde ayrılıp yeni mecra arayışına girebilirler ya da dahil oldukları ortamdaki kolektif zekanın bir parçası olmaya devam edebilirler.

Jenkins'in kitabında bahsettiği “kolektif zeka”, tüketimin kolektif zekanın bir ürünü olduğu savından hareketle Pierre Lévy (1999) tarafından ortaya atılmıştır. Lévy’e göre sanal toplulukların üyeleri bilgi ve uzmanlıklarını katılımcı işbirliğinin sonucu olan kolektif zeka ile geliştirirler. Sanal toplulukların ilişkileri her ne kadar "gönüllü, geçici ve taktiksel ilişkilerle" tanımlansa da (Jenkins, 2019, 50), bu yeni toplumsallıkların üyeleri çıkarları doğrultusunda birleşirler, ayrılırlar; yeniden bağ kurarlar veya ihtiyaçları dahilinde başka gruplarla, topluluklarla aidiyet kurabilirler. Ortak menfaatlerin meydana getirdiği karşılıklı bilgi alışverişi, "herhangi bir zamanda kendisi için mevcut ilgili bilginin tümünü” erişebilir hale getiren kolektif zeka ile mümkündür (Lévy, 1999, 217). Buna karşın, dijital ortamda bir sanal toplumun üyelerini ve dolayısıyla "kolektif zekayı bir arada tutan şey, bilgiye sahip olmak -nispeten statiktir- değil, bilgi edinmenin sosyal sürecidir- dinamik ve katılımcıdır, devamlı grubun sosyal bağlarını test eder ve yeniden tasdik eder" (Jenkins, 2019, 85). Böylelikle kişi, kendine sunulan imkanlar dahilindeki demokratik dürtüsüyle bir yapılanma ve yapılandırma sürecine girebilir. Katılımcı yakınlaşma kültürü, kimlik inşası sürecini, çevrimdışı ortamda olduğu gibi çevrimiçi dijital ortamda da şekillendirebilir (Jenkins, 2006b, 5; Kurmel ve Süter-Görgüler, 2020).

Kişilerin ağdan uzak kaldığında “dünyadan uzaklaşmış, olan bitenden habersiz (Karakartal, 2013, 5)" hissettiği sosyal ağlar, üyelerine kendilerini tanıtma, kendileriyle ortak hobi ve/veya beğenilere sahip, aynı fikir ve düşünceleri paylaştıkları farklı kişilerle bir arada olma firsatını sağlar. Bu firsat kişilere, "yüz yüze ilişkilerde gerçekleştiremedikleri kimlikleri inşa etme şansı verir” (Zhao, 2008, 1819'den aktaran Sütlüoğlu 2015, 128). Facebook gibi kişilerin anonim olmayan profiller oluşturup ortak uzlaşı ortamı yaratarak yakınsama kültürü oluşturduğu dijital ortamlar, aynı zamanda bireylere ortak bir kimlik inşası fırsatı da tanır. Karakoç ve Gülsünler'e göre katılımcıları Facebook kullanmaya yönelten motivasyonlar, "eğlence", "bilgilenme/ arkadaşlık", "rahatlama/ sosyal kaçış" ve "sosyal etkileşim”dir $(2012,55)$. Köseoğlu da üniversite öğrencilerinin Facebook kullanma güdülerini tespit etmek amaciyla “kullanım ve doyumlar yaklaşımı”nı esas alarak çalışmasının sonucunda bunları, "fotoğraf/ 
video, kullanım kolaylığı, topluluk gündemini yakalama, magazin konuları, kullanım tercihleri ve sosyal bağlantılar” şeklinde sıralamıştır $(2012,58)$. Demez'e göre ise, gençler Facebook'u, "bilgi edinme", "kendini ifade etme" ve "kimlik kurgulama", “oyun oynama", "görünür olma", "gözetleme", "teşhir etme", "açılma" ve "sosyalleşme" benzeri amaçlarla kullanırken "sosyal medya; bireylerin, farklı grupların, farklı kimlik kurgularını, yönlerini ifade ettikleri, sakladıkları, savundukları, mücadele ettikleri, ilişkilerini kullandıkları bir mecraya dönüşmüş durumdadır" (Demez, 2013, 446). Sütlüoğlu ise gençlerin sosyalleşme ve kimlik inşası süreçlerini incelediği çalışmasında Facebook’ta inşa edilen kimliklerin, "sanal dünyada üretilen dilin tüm olanaklarını da kullanarak, bireyin gerçekte sahip oldukları ve arzuladıkları arasında kurulan dengeyle yeniden inşa edilmekte ve giderek daha melez bir yapıya bürünmekte" olduğu sonucuna varmıştır $(2015,142)$. Elbette dijital ortamda iletişim ve etkileşimin bu melez yapıyı ve yeniden inşayı sürdürülebilir konuma taşımasında çeviri pratiğinin rolü oldukça önemlidir.

\section{Dijital Ortam Çeviri Pratikleri}

Johan Heilbron ve Gisèle Sapiro, çeviriyi, "toplumsal bir pratik ve uluslararası düzlemde gerçekleşen kültürel değiş-tokuşların itici gücü olarak ele almak gerektiğine dikkat çekerek, çeviri pratiğine katılan birey ve kurumlardan oluşan tüm eyleyicilerin, çeviri çözümlemelerine dâhil edilmesinin zorunluluğuna" vurgu yaparlar (2007, 104). Aynı şekilde çeviri sosyolojisi, çeviri ürünün arkasındaki dinamiklere ve bu dinamiklerle ilgili eyleyicilerin deneyimlerine odaklanır (Bogenç-Demirel, 2014, 408-409). Yükselen yeni toplumsallıklarla, farklı ortamlarda etkileşimsel bir misyon edinen çeviriyle birlikte, çeviri sosyolojisi de "toplumsal değişkenleri teşhis etme görevini üstlenir” (Bogenç-Demirel ve Süter-Görgüler, 2019, 80). Çeviri alanında yaşanan sosyolojik dönemeçle birlikte gündeme gelen ă̆ temelli yeni toplumsallıklar ve demokratikleşme hareketi (Bogenç-Demirel ve Süter-Görgüler, 2019; Bogenç-Demirel, SüterGörgüler ve Kurmel, 2017; Bogenç-Demirel, 2014') çeviri alanında dijital ortama açılmanın ve eyleyicilerin dijital ortam çeviri pratiklerini sahada odağa almanın önemini ortaya koyar. Bu sebepten öncelikle Bulgaristan göçmenlerinin dil ve çeviri pratiklerini anlamaya çalışmak uygun olacaktır.

Bulgaristan'dan Türkiye'ye göç eden göçmen topluluklarının toplum-dilsel durumu hakkında henüz detaylı bir özgün çalışma yapılmış olmasa da Bulgaristan göçmenlerinin deneyimledikleri “dil değiştirimi”" (göç sürecinde dilsel pratiklerinde gözlemlenen değişiklikler) süreci aşikârdır (Bosnalı ve Şafak, 2017, 141). Göç dalgaları sebebiyle Bulgaristan'da yaşayan Türk nüfusunun azınlıkta kalması, Bulgarcanın resmi dil olup "Türkçenin topluluk içindeki iletişim ve kültür aktarımını" sağlayan bir dil konumuna gelmesine yol açmıştır (Bosnalı ve Şafak, 2017, 142). Topluluğun dilindeki bu ikilik ayrı bir dil topluluğunun, dolayısıyla ayrı bir iletişim ağının oluşumuna zemin hazırlamıştır. Türkiye Türkçesinin Rumeli ağzıyla konuşan

1 Dijital ortam çeviri pratikleri ve bununla ilgili kavramsallaştırmalara ilişkin daha fazla kaynak için bkz. (BogençDemirel \& Süter-Görgüler, 2019, 84-85). 
Bulgaristan göçmenleri (Banguoğlu 1977, 133), hem göç ettikleri bölgenin yerli ağzından hem de doğup büyüdükleri bölgenin dil özellerinden etkilenip dil değiştirimi olgusuna örnek teşkil etmektedir. Diller arasında girişiklik ve dönüştürümün sıklıkla görüldüğü dil değiştirimi, söz konusu göçmenlerin dijital ortamda gerçekleştirdikleri dil ve iletişim pratiklerine de fazlasıyla yansımıştır. Coğrafi değişim ve kültürel değiş-tokuşun etkisiyle, Bulgarca, Rusça, Türkçe dilleri arasındaki çeviri pratiği de Bulgaristan göçmenlerinin dijital ortamdaki eylemlerinin doğal bir sonucu haline gelmiştir.

\section{Yöntemsel Yaklaşım: Netnografi}

Bu çalışmada kullanılan yöntem, Kozinets tarafından literatüre kazandırılan "netnografik" araştırma yöntemidir (2010). Çalışma Facebook sosyal ağında kurulan kapalı bir grupta paylaşım yapan eyleyicilerin seslerine netnografik bir yaklaşımla odaklanmıştır. Kozinets tarafından 1990’lı yılların sonunda geliştirilen Netnografi yöntemi, geniş bir çerçeveden bakıldı̆̆ında “internet veya ăg etnografisi”"dir. Kozinets “teknoloji aracılığıyla anında arşivlenen iletişimi” bir araştırma alanı olarak tanımlar ve yüz yüze etnografi gibi, netnografinin de grupların hayatlarını nasıl geçirdiklerini göstererek onların gerçeklerine doğru bir pencere açtığını ifade eder (2010, 1-11). Kozinets'e göre netnografi, "etnografi gibi doğalcı, katılımcı, tanımlayıcı, çok metotlu, uyarlanabilir ve bağlam odaklıdır" (2010, 1). Hatta odak gruplarıyla yapılan anket, röportaj gibi ve/veya odak grupları üzerinde geliştirilen yapay niceliksel modellere kıyasla netnografik araştırma yöntemi "doğalcı" ve "kültürel içgörülere dönüştürülecek sosyal medya verilerinin oluşturulması için antropolojiye dayalı, sağlam bir yöntem”dir (Kozinets, 2010, 1). Bu sağlam yöntemle, dijital izlerinden hareketle araştırılan "kültür üyelerinin yerel dili, tarihi, oyuncuları, uygulamaları ve ritüelleri, kültürel etkileşimi ve eğitimi”" hakkında "müdahale edilmemiş veri”" hakkında bilgi sahibi olmak mümkündür (Kozinets, 2010, 11-12). Netnografi, geleneksel etnografik araştırma yönteminden adapte edilen ve sahası internet olan nitel bir araştırma yöntemidir ve bu araştırma yönteminde "katılımsız ve katılımcı gözlem, içerik, söylem ve tematik çözümleme gibi alt araştırma teknikleri öne çıkmaktadır" (Kozinets, 2006, 280-281'den aktaran BogençDemirel ve Süter-Görgüler, 2019, 85). Netnografik araştırma yöntemi, bireylerin deneyimlerinden oluşan toplumsal olguları, doğal bağlantılardan kopmadan inceleme firsatı sunmaktadır. Biz de çalışmamızda netnografik yöntemsel yaklaşımı, Jenkins' in yeni medya pratiklerini analiz ettiği “yakınsama kültürü” ve "katılımcı kültür" kavramlarıla, Lévy’nin bilgi toplumu ve enformasyon teknolojilerine bağlı değişimleri incelediği "kolektif zeka" (1999) kavramı ve Castells'in "ağ toplumu" kavramı ile buluşturup bu yeni ve dinamik alanda somut bir adım atmaya çalıştık (Krş. Dahan ve Levi, 2012, 35; Özbölük, Dursun, 2015, 227-229).

\section{A ğda İz Sürmek}

Netnografik araştırma yöntemi kapsamında araştırmaya yön veren sorular ve konu başlıklarını tespit edildikten sonra, "Balkan Göçmenleri”, "Bulgaristan göçmenleri”, "Kurcaali”, "Benkovski”" gibi Bulgaristan ve Balkan göçmenlerini, göçmenlerin yoğunlukla yaşadıkları yerleri çağrıştıran 
belirli anahtar sözcükler Google arama motorunda aratılmıştır. Bu sayede Balkan göçmenlerinin üye olduğu çeşitli sosyal medya gruplarına ulaşılmıştır. Bu gruplar içerisinden Facebook üzerinde kurulmuş takipçi sayısı fazla olan kapalı gruplardan birisi seçilmiştir. Grup içerisinde detaylı, içeriği zengin ve güncel verilerin olması ile üyeler arası etkileşimin sürekli olması sebebiyle çalışmanın araştırma grubu olarak bu grup belirlenmiştir. Platform konu başlıkları çerçevesinde incelenmiş ve veri toplama aşamasına geçilmiştir. Gruptan elde edilen ham veriler, görsel bulgular ile birlikte, tematik olarak gruplandırılmıştır. Bu aşamada, "araştırmacının herhangi bir katılımı olmaksızın kopyalanarak elde edilen arşivsel veri”, anında yorum ekleme yoluyla ve "araştırmacının topluluk, topluluk üyeleri ve üye etkileşimleriyle ilgili gözlemlerini yazarak oluşturduğu saha notu verileri” bu çalışmada değerlendirilen ham veri grubunu oluşturmaktadır (Kozinets, 2010, 98). Bahsedilen saha notu verileri, harf ve rakamların oluşturduğu yazılı verinin yanında, his simgelerinden (emojiler) fotoğraflara kadar görsel ve grafiksel verileri de kapsamaktadır.

\section{Netnografik Çözümleme}

İlgili çevrimiçi grupta gerçekleştirilen netnografik saha çalışmasından elde edilen ham veriler, makro düzeyde grubun ana sayfasında bulunan grup açıklaması, grubun amaç ve hedefleriyle birlikte değerlendirilerek belirli temalara ulaşılmıştır. Mikro düzeyde ise ulaşılan temalar 1şığında çevrimiçi saha notları netnografik içerik çözümlemesine tabii tutulmuştur.

\section{Sahadan İlk Sesler: Grup Özellikleri}

WEB 2.0'1n sunduğu hizmetler ve bu hizmetler sayesinde dijital ortamda gerçekleştirilen pratiklerin hayatlarımızın vazgeçilmez bir parçası durumuna gelmesi, bireylerin alışkanlıklarının değişmesiyle birlikte kendilerinin de değişip dönüşmesi göz ardı edilemez bir gerçektir. Önceleri sınırlar ötesine ulaşmanın uzun uğraşlar ve süreler sonucunda ancak mümkün olabiliyorken günümüzde hızlı, etkileşimsel iletişim olanakları, bireyler arasında anlık, kullanıcı türevli içeriklerin paylaşımları mümkün kılmış; bireyleri de dijital ortamın gönüllü, katılımcıpaylaşımcı aktörlerine dönüştürmüş ve kitlesel iletişim, akışkan örgütsel davranışları görünür hale getirmiştir. Dijital ortamın "en çok kullanılan sosyal medya platformu olan Facebook, “dünya nüfusunun yüzde 28,5'inin aktif olarak kullandığı ve toplam kullanıcı sayısının 2 milyar 167 milyona" dayandığg bir sosyal ağ olarak Bulgaristan göçmenlerinin de aktif katıldığı bir platformdur ("Facebook kullanıcı sayısı 2,7 milyara ulaştı". 17.03.2021). Özellikle Facebook'ta yer alan kapalı gruplar, Bulgaristan göçmenlerinin kolektif kimlikleri, dijital ortamdaki yakınsama/yakınlaşma kültürünü ve bu ortamda çevrilen toplumun izdüşümlerini yansıtan hiper-metinsel ham verilere anlık, hızlı, ücretsiz ulaşımı sağlamaktadır.

Grup, Facebook sosyal paylaşım ağında 18 Temmuz 2013 tarihinde kurulmuş olup 17.03.2021 tarihi itibariyle 48.088 üyesi bulunan, Facebook üzerinde takipçi sayısı en fazla olan kapalı grup olma unvanına sahiptir. Grubun bir yöneticisi, bir de moderatörü bulunmaktadır, grubun yöneticisi ve aynı zamanda grubun kurucularından biri, Bulgarca-Türkçe çift dilli bir 
gazetede köşe yazarlığı yapmakta ve grupta bu gazeteden de paylaşımlara yer vermektedir. Grupta binlerce eyleyen iki dili paylaşımların dolaşımına katılmakta ve bu çok dilli platformda katılımcı demokrasi, özgürlükçü ve çok yönlü aktif bir dönüşüm gerçekleştirmektedir. Fakat demokratik fikir paylaşımına kapılarını açan grup, evrensel ahlaki değerler ışığında nefret söyleminden, şiddetten ve olabildiğince olumsuz eleştirilerden uzaklaşmayı amaçlamak üzere yöneticilerin koyduğu grup kurallarına da sahiptir.

\section{Yöneticilerin Grup Kuralları}

\section{Kibar ve Nazik Ol}

Samimi bir ortam oluşturmak hepimizin sorumluluğu. Herkese saygııı davranalım. Kibar olduğumuz sürece yapıcı tartışmalar doğaldır.

2 Nefret Söylemlerine veya Zorbalığa İzin Verilmez

Herkesin güvende hissettiğinden emin ol. Zorbaliğın hiçbir türüne izin verilmez ve ırk, din, kültür, cinsel yőnelim, cinsiyet veya kimlik gibi konularda yapılan küçük düşürücü yorumlara hoşgörü gösterilmez.

3 Tanıtım veya Spama İzin Verilmez

Bu grupta aldığından daha fazlasını ver. Kendi reklamın yapmaya, spama ${ }^{\cdots}$ ve alakasız bağlantılara izin verilmez.

\section{Herkesin Gizliliğine Saygı Göster}

Bu grubun bir parçası olmak, karşııklı güven gerektirir. Özgün, anlamlı tartışmalar grubu güzelleştirir ama hassas ve mahrem de olabilir. Grupta paylaşılanlar grupta kalmalıdır.

\section{Resim 1: Yöneticilerin Grup Kuralları}

Grubun ana sayfasında bulunan grup açıklaması, grubun amacı ve yapılan paylaşımların ortak temaları hakkında bariz ipuçları vermektedir. Grup açıklaması uzun bir metin olmakla birlikte, açıklamanın özetle anadilde eğitim hakkı, ibadethane, tarihi eser gibi yapıların tahrip edilmesi gibi hassas konularda grup üyelerini bilinçlendirme misyonu edindiği anlaşılmaktadır. Grup açıklaması, yakınsama duygusunun kaçınılmaz rolünün en önemli kanıtlarından biridir.

Grup, katılım ve paylaşımın üst düzeyde ve grup içi dinamiğin hızlı bir yayılımla gerçekleştiği, kullanıcıların/üyelerin demokratikleşerek yapılandığı bir sosyal ağ platformudur. Aşağıda 13.03.2021 tarihli ekran görüntüsü grup içi dinamik ve dolaşım hakkında değerli bilgiler vermektedir: 


\section{Grup Hareketleri}

\section{B Bugün 153 yeni gönderi \\ Son 28 günde 8.900 \\ Toplam 48.088 üye \\ Geçen hafta +37 \\ Oluşturulma zamanı: 8 yıl önce}

Resim 2: Grup içi dinamik ve dolaşım

Netnografik çözümleme yönteminin kullanılacağı bu çalışmada, yapılacak olan çevrimiçi metin temelli çözümleme öncesi, Bulgaristan göçmenlerinin aktif katılım sağladığg kapalı gruplar bazı filtreleme kriterlerinden geçirilmiş ve grup bu filtreleme kriterleri ışığında değerlendirilerek seçilmiştir. Kriterler aşağıdaki gibidir:

Araştırma sorusuna en uygun olan ve konusuna en fazla yoğunlaşan topluluk olması;

Münferit mesajlara yer verilmesi;

Detaylı ve içeriği zengin verilerin olması;

Üyeler/katılımcılar arası etkileşimin sürekli gerçekleşmesi;

Takipçi sayısının yüksek sayılara ulaşması ve

Forum sayfalarında güncel veri akışının sağlanmasıdır

(Bogenç-Demirel, Görgüler ve Kurmel, 2017, 3).

Elde edilen veriler, netnografik çözümlemesi yapılacak olan kapalı grubun araştırma konusu olarak seçilmesinde verilen doğru kararın bir tasdiki niteliğindedir. Bu çerçevede saha çalışması öncesinde geliştirilen araştırma soruları şöyledir: "Grupta yapılan paylaşımlar göz önüne alındığında, ağ toplumunda, netnografik çözümleme 1şığında topluluk üyelerinin sergiledikleri “yakınsama kültürü” ve "katılımcı kültür”e özgü davranışlar, çevrimiçi/dijital ortama nasıl yansımaktadır?" ve "ağ içerisindeki eyleyenler dijital ortam çeviri pratiklerini nasıl inşa etmektedir?”.

Bu kısımdan itibaren çalışmadan elde edilen saha notu verileri, netnografik çözümleme ilkeleri doğrultusunda değerlendirilecek ve alan-yazın taraması ve saha çalışmasıyla geliştirilen araştırma sorularına yanıt verilmeye çalışılacaktır.

\section{Netnografik İçerik Çözümlenmesi}

İlgili grupta gerçekleştirilen netnografik pusu doğrultusunda elde edilen verilerden, aktif katılımcı grup üyelerinin paylaşımlarının çoğunlukla dijital ortamda oluşturulan yakınsama/ yakınlaşma kültürü (Jenkins, 2006a) ve kolektif zekanın (Lévy, 1999) izdüşümünü yansıttığı anlaşılmaktadır. Örneğin, Bulgaristan'dan yapılan göçlerin tarihi, göçler esnasında yaşanan zorlu 
tecrübelerle ilgili paylaşımlar, katılımcıların çoğunlukla yorumda bulunup ifade bıraktıkları, kimlik aidiyetinin dijital ortama yansıdığı paylaşımlardır. Sosyal medya ağlarının kişilerin “dolayımlı" ilişkiler kurdukları ve bağlantılarını sınır tanımadan uzaktan yürüttükleri ve Bourdieu'nün deyimiyle "seçici yakınlıklar kurma eğilimi”ni arttırdıkları araçlar (Bourdieu, 1984, 241'den aktaran Gerbaudo, 2013, 57) oldukları düşünülürse bu son derece doğaldır. Grupta en çok beğeni ve yorum alan paylaşımlardan biri de "Cep Herkülü: Naim Süleymanoğlu” filminin televizyon kanallarındaki gösterimlerinin duyurularının olduğu paylaşımlardır. Bulgaristan doğumlu, 7 Dünya Rekoru sahibi Süleymanoğlu'nun dramatik hikayesini konu alan bu filmle ilgili paylaşımların gruptaki dinamizmi arttırma sebepleri arasında, Bulgaristan Türklerinin/göçmenlerinin kendilerini ve geçmiş tecrübelerini filmin başrolüne yakınsaması olduğu düşünülmektedir. Bunun yanında, özellikle "günaydın/iyi akşamlar” gibi grup içi dinamiği hızlandıran “yaratıcı aktivist taktikler” (Boyd ve Mitchell, 2015, 1-2), grupta en çok yorum alan paylaşımların başında yer almaktadır (bkz. Resim 3).

\section{Bu Gruptaki Popüler Konular}

\#iyigeceler

38 gönderi

\#iyiakşamlar

22 gönderi

\#insan

4 gönderi

Resim 3: Gruptaki Popüler Konular

Aynı şekilde Bulgaristan doğumlu şehitlerin haberlerinin de yorum trafiğini arttırdığı söylenebilir. Bu gibi paylaşımlarda, katılımcıların yorumları arasında Türkçe, Bulgarca, Rusça ve/veya Kiril alfabesiyle yazılan Türkçe ifade ve cümlelere sıklıkla rastlamak mümkündür.

Grubun doğal akışının, yakınlaşma/yakınsama kültürünün yansıması olduğunu iddia etmek yanlış olamayacaktır. İlgili dijital ortamdaki katılımcılar, hem sevinç, coşku, mutluluk gibi hem de hüzün, öfke, kin gibi duygu ve hisleri bir araya gelerek tecrübe etmektedir. Örneğin, Bulgaristan'da yaşayan Türklere karşı yapılan yıpratma politikalarıyla ilgili paylaşımlardaki kenetlenme duygusu, karşı ataklara hassasiyet gösterilen mücadeleli bir alana (ç)evrilmiş, Durkheim'ın "toplu coşma" anı olarak tanımladığı "toplanma olgusu, istisnai derecede güçlü bir uyarıcı" olarak bireyleri bir araya toplayıp aralarında olağan dışı bir elektrik üretmiştir (Durkheim, 1912/1965, 162). Jenkins bu olguyu, katılımcı kültürün beraberinde getirdiği yakınsama kültürü kavramıyla açıklamaktadır. Yakınsama kültürünün, grup üyelerinin doğal ve anlık tepkilerini, grup kurallarını görmezden gelerek ortaya koymalarına sebep olduğu söylenebilir. Özgürlükçü fikir paylaşımı, bazen nefret söylemine karşı nefret söylemini tetikleyebilir. Bu bağlamda, kolektif hassasiyetin meydana getirdiği ortak kimliğin yeniden inşa edildiği ifade edilebilir. 
"Facebook halka dayalı kimlik oluşturmakta duygusal bir toplanma noktası hizmeti" gördüğünden Bourdieu'nün "seçici yakınlık” dediği, "birlikte yürüyen insanları bir araya getirme" eğilimini ortaya çıkarır (Gerbaudo, 2013, 239-245). Ağ toplumlarına özgü bu toplumsal örgütlenme davranışı, aslında "ağ toplumu” kavramının işaret ettiği toplumsal dönüşümün yansımalarını da gözler önüne sermektedir. Dahil oldukları ağda, Jenkins'in deyimiyle yakınsanan eyleyiciler, ağla birlikte değişir ve dönüşürler. Birlikte deneyimledikleri yabancılaşma/soyutlanma hissi ise çevrilen ağ toplumunun ayak izleridir. Örneğin, katılımcı kültürün yansıması olarak grup üyelerinin yıllar öncesine ait, Bulgaristan'daki yaşamlarının izlerini taşıyan fotoğrafları paylaşarak geçmişe duydukları özlemi yorumlarında dile getirmeleri, değişen ve dönüşen toplumun bir işaretidir. Bu tip paylaşımlar, katılımcı-paylaşımcı kültüre özgü yatay kolektivizmin dijital ortama yansımalarına örnek gösterilebilir. Grup üyelerinin geçmişe duydukları özlemle birlikte sergiledikleri kolektif zeka, Facebook'ta varlık arttırma ve duygusal saf tutma taktikleriyle kendini göstermiştir. Eyleyicilerin varlık arttırıp duygusal saf tutarken reaksiyon alması muhtemel "emoji", "smiley", "emoticon" gibi görsel ifade sembollerini kullanmalarının ardındaki neden en yüksek olasılıkla ilgi çekme, reaksiyon alma isteğidir. Benzer fotoğrafların grup içinde en çok beğeni alan paylaşımlardan olduğu düşünülürse ağdaki kolektif zekayı pekiştiren Bulgaristan'dan fotoğraf paylaşma taktiğinin işe yaradığı çıkarımına ulaşılabilir. Bu tip paylaşımların çoğunlukla görsel malzemeden oluşması da imgelerin yakınlaşma/yakınsama kültüründe sahip olduğu gücün bir kanıtıdır.

İlgili grup, en az iki ülkeyi, dili, dini, kültürü içinde barındıran ve bu öğelerin birbiri içinde akışkan dönüşümünün hızlı, anlık ve öngörülemez bir şekilde gerçekleştiği bir sosyal medya platformudur. A ̆g merkezsizdir (Castells, 2013), bu sebepten grup katılımcı bir şekilde demokratiktir. Ağda önemli olan ağın devamlılığını sağlamaktır. Bunun için ağı "halka tanıtmak", "geniş kitlelere yaymak", ağda olabildiğince fikir paylaşımında bulunmak ve bunu hızlı yayılımla gerçekleştirmek ağın sürdürülebilirliği için esastır. Eyleyicilerin uyguladığı bu taktiklerle, "bireysel bir dönüşüm aslında toplumsal bir dönüşümü” tetiklemektedir (Bogenç-Demirel ve ark., 2017). Örneğin, üyelerin Bulgarca paylaşımlarının altına yapılan Türkçe, Rusça, Bulgarca ve hatta Kiril alfabesiyle yazılan Türkçe ifadeler, dijital ortamdaki çeviri pratiğinin göstergesidir. Öyle ki grubun doğal akışının bir parçası olan çoklu dil kullanımıyla, katılımııların çeviri sürecinin eyleyici aktörleri konumuna taşındığı ve kimlik aidiyeti şuurunun da dönüştüğü, çevrildiği de gözlemlenebilmektedir. Örneğin, katılımcıların paylaşımlarından birinde yer alan "bırçet" sözcüğü, Bulgaristan Türklerinin akranlarına seslenirken kullandığı, Bulgarcada "kuzen" veya "yeğen" anlamına gelen bir sözcüktür. Grup içinde buna benzer çeşitli Bulgarca hitap şekillerinin Türkçe ifade edilen cümlelerde kullanılması, yakınsama kültürünün etkisiyle gruba özgü kavramların ortaya çıkmasıyla açıklanabilir. Bir başka paylaşımda, önceden Bulgaristan'da sıklıkla kullanılan Rus yataklarının görselinin altına "Rusensko Leglo [Русенско Легло / Rus Yatağı] tıngır tıngır oynayan yataklardan” yorumuna rastlanmıştır. Aynı görselin altına "Çok güzel günlerdi, nerede kaldı”, "herkes misafir gelirdi şimdi kimse kimseye gitmiyor” gibi 
serzenişlerin de mevcut olduğu görülmüştür. Bulgaristan'dan farklı bir paylaşımda, “4 yıl dirvodeleslik [дърводелец / marangozluk] yaptım çok iyi anılarım var, unutulmaz arkadaşlar vardı. Hep dağıldık koca şehir İstanbul yedi bizleri” yorumu dikkat çekmektedir. Bulgarca bir sözcüğün, Türkçe cümle yapısı ve söz dizimiyle oluşturulan bir cümlede yadırganmadan kullanılması veya tam tersi bir biçimde, yorumlarda Latin alfabesiyle yazılan Bulgarca, Rusça ifadelere rastlanması, dilin ve toplumun çeviri pratiğiyle değişim ve dönüşümünün bir örneğidir. Ayrıca ortak paylaşılan geçmişe özlem duygusu, bu dönüşümün bir diğer yansımasıdır. Grup içinde amaç, ağın sürdürülebilirliğine hizmet etmektir. Bu amaç gerçekleşirken üyelerin belki de farkında olmadan aldıkları çevirmen konumları, ağ içi katılımcı kültürün yansımalarından biridir. Grup üyelerinin grupta paylaşılan duyurulara, “Дору лафа не дерсин” [Kiril alfabesiyle Türkçe ifadenin sözcüğü sözcüğüne çevirisi: Doğru lafa ne dersin], “ейваллах” [еyvallah] gibi yorumları, yakınsama kültürünün çeviriyle temsili olarak değerlendirilebilir. Dikkat çeken başka bir örnekte, “щастлива вечер” [Mutlu Akşamlar] yorumu, bir Türk üye; 24 Aralık’ta Noel'i kutlamak amacıyla "yeni yılınız kutlu olsun" yorumu da bir Bulgar üye tarafindan paylaşıldığı görülmüştür. Aynı şekilde, 31 Aralık gecesi yeni yılı kutlamak amacıyla paylaşılan bir gönderinin altındaki “ÇESTITA NOVA GODINA NICE MUTLU YILLARA” yorumu iki dili bir araya getiren çeviri eyleminin izdüşümüdür. Buna göre, ağdaki eyleyenlerin, deyim yerindeyse birbirinin kimliklerine ve dillerine çevrildiği iddia edilebilir. Dolayısıyla, dilin, kültürün ve hatta kimliklerin çevrildiğini iddia etmek yanlış olmayacaktır.

\section{Sonuç Gözlemleri}

“Ağ toplumunun yükselişis”yle birlikte ortaya çıkan yeni toplumsallıklar (Castells, 2005), katılımcıların demokratik, dinamik ve paylaşımcı "ortak bir üretim alanında" konumlandığı dijital ortamlardır (Bogenç-Demirel ve Süter-Görgüler, 2017, 313). Katılımcılar arasındaki iş birliği ile kolektif üretimin inşa edildiği dijital ortamdaki çevrimiçi topluluklar, bireylerin etkileşimsel bilgi paylaşım platformlarıdır. Ağ toplumu ve çevrimiçi ağların günümüzdeki yapılandırıcı işlevi, ağdaki aktörlere "arşivleme, açıklama, uygunlaştırma ve tekrar dolaşıma sokma olanağı sağlayarak yeni bir katılımcı halk kültürüne yani katılımcı yakınsallığa” teşvik etmektedir (Turhan, 2017, 308).

Çalışmanın yöntemsel yaklaşımı netnografi, çevrimiçi kültürel iç görüleri yansıtan sanal toplulukları incelemek ve araştırmacıların doğrudan ham veriler üzerinden elde edebileceği değerli çıkarımlarına olanak sağlayan çeşitli kültürel çalışmaları yürütmek için geliştirilmiştir. Akademik dünyanın en yeni, dinamik ve çoklu ortamlara uygulanabilir, sahası internet olan nadir araştırma yöntemlerinden biridir. Bu yöntemin kullanıldığı araştırmanın sonucunda sahadan elde edilen ham veriler ne kadar önemliyse verilerin çözümlenip değerlendirilmesi de aynı derecede büyük önem taşımaktadır.

Saha notlarından elde edilen bulgulardan hareketle, çalışmanın başında öne sürülen araştırma sorularına verilen yanıtlar, grupta yakınlaşma kültürünün etkisiyle yeni bir katılımcı kültür ve kolektif zekanın oluştuğunu; paylaşımlarda bulunan eyleyicilerin kendileri yapılanırken içinde 
bulundukları dijital ortamı ve dolayısıyla diğer eyleyicileri yapılandırdığını göstermektedir. Bu bağlamda katılımcı kültür, grup içerisindeki her bir bireyin var olabilmek ve daha fazla içerik üretebilmek için mücadele verdiği bir dolaşıma sebep olmuştur. Netnografik çözümlemeden hareketle, grup içindeki var olma ve duygusal saf tutma mücadelesinin, kullanıcı türevli içeriklerin daha fazla üretilmesini teşvik ettiği söylenebilir. Dolayısıyla eyleyicilerin katkıda bulunduğu her bir paylaşımda ağı sürdürülebilir konuma taşımak için dolaşımın sürekliliğini sağlama gayretinde olduğu iddia edilebilir.

Grup, Türkçe ve Bulgarcanın dolaşıma dahil olduğu en az iki dilli bir sosyal ağ platformu olmak üzere çok dilli, çok katmanlı ve kendi içinde çeviri pratiğinin sürekli gerçekleştiği aktif bir platformdur. Zaman zaman Rusçanın da iletişim dillerine dahil olduğu grup, kendine özgü melez iletişim dili/dilleriyle çevirinin toplumsal inşa işlevini yansıtmaktadır. Devamlı ve tekrarlı temaslarla yapılan saha çalışması ve ardından gerçekleştirilen netnografik içerik çözümlemesi doğrultusunda ağ içerisindeki eyleyenler, grubun doğal akışındaki çeviri inşasının birer aktörü konumunu almışlardır.

Sonuç olarak, netnografik içerik çözümlemesi odağında, topluluk üyelerinin sergiledikleri ağ toplumuna özgü kolektif davranışlarla çevrilen toplum, çevrimiçi/dijital ortamda çok sesli, çok dili, çok katmanlı, demokratik, katılımcı-paylaşımcı, yakınsama olgusunun özgürlükçü birer eyleyicisi olarak karşımıza çıkmaktadır. Bu bağlamda eyleyicilerin, grup kuralları dahilinde olabildiğince nefret söyleminden uzak, evrensel ahlaki değerleri gözeten ve bireysel girişimcilikle toplumsal dönüşümü harekete geçiren birer aktör konumunda olduğu iddia edilebilir. Halihazırda yaşam ortamının, dilin, kültürün değişmesiyle kendi değişim ve dönüşümünün öznesi ve aynı zamanda nesnesi olan Bulgaristan göçmenlerinin, çeviri pratiğini dijital ortamın etkileşim ve dönüşümünde bir yeniden üretim aracı olarak kullandığını iddia etmek yanlış olmayacaktır. $\mathrm{Bu}$ durumda toplumların ve kültürlerin değişim ve dönüşümünün başat rolü çevirinin, yeni medya ve dijital ortamdaki etkisinin göz ardı edilemeyeceği ortadadır.

Hakem Değerlendirmesi: Dış bağımsız.

Çıkar Çatışması: Yazar çıkar çatışması bildirmemiştir.

Finansal Destek: Yazar bu çalışma için finansal destek almadığını beyan etmiştir.

Peer-review: Externally peer-reviewed.

Conflict of Interest: The author has no conflict of interest to declare.

Grant Support: The author declared that this study has received no financial support.

\section{KAYNAKÇA/REFERENCES}

“Asimilasyon ve Göç: Bulgaristan Türkleri’nin Öyküsü”. CNN Türk. Erişim Tarihi: 17.03.2021. Cnnturk.com: https://www.cnnturk.com/haber/turkiye/asimilasyon-ve-goc-bulgaristan-turklerinin-oykusu Banguoğlu, T. (1977). Anadolu ve Rumeli Ağıları. Türk Dili ve Edebiyatı Ansiklopedisi, 1, 132-134. Binark, M. \& Löker, K. (2011). Sivil Toplum Örgütleri için Bilişim Rehberi, STGM, Ankara. Binark, M. (2014). Yeni medya çalışmalarında araştırma yöntem ve teknikleri. Ayrıntı Yayınları. 
Bogenç-Demirel, E. (2014). Çevirinin Bourdieu Sosyolojisiyle yapılanan yüzü, Çeviri Sosyolojisi. Cogito, (76), 402-416.

Bogenç-Demirel, E., Süter-Görgüler, Z., \& Kurmel, D. (2017). Ağ Toplumunda Çeviri Odaklı Demokratik Pratikler. 21. Türkiye'de İnternet Konferansı (INNET'16), TED Üniversitesi, Ankara, Turkey.

Bogenç Demirel, Z. E., \& Görgüler, Z., (2017). Yeni Toplumsallıklar Etrafında Yükselen Çeviri Eğitimi: Çevrimiçi Fan Toplulukları ve Sahadan İlk Sesler. Hacettepe Üniversitesi Frankofoni Dergisi, 303-315.

Bogenç-Demirel, Z. E., \& Süter-Görgüler, Z., (2019). Yeni Toplumsal Hareketlerin İşaret Fişeği: Evrim Ağacı Topluluğu ve Darwin'i Yeniden Çevirmek. Hacettepe Üniversitesi Frankofoni Dergisi, 34, 79-93.

Bosnalı, S., \& Şafak, Z. (2017). Bölüm 12. Bulgaristan Türk Göçmenlerinde Dil Değinimi. Göç Üzerine Yazın ve Kültür İncelemeleri içinde, 141.

Bourdieu, P. (1984). Distinction: A social critique of the judgement of taste (Richard Nice, Trans.) Cambridge, Massachusetts: Harvard University Press.

Boyd, A. \& Mitchell, D. O. (2015). Bela İyidir. Devrim Kılavuzu (Baran Akkuş, Çev.). Ankara: Bilgi Yayınları.

Castells, M. (1996). The Rise of the Network Society. The Information Age: Economy, Society, and Culture Volume I (Information Age Series). London: Blackwell.

Castells, M. (2005). Enformasyon Çă̆ı: Ekonomi, Toplum Ve Kültür Birinci Cilt Ağ Toplumunun Yükselişi 1 (Ebru Kılıç, Çev.). İstanbul: İstanbul bilgi Üniversitesi Yayınları.

Castells, M. (2013). 'Ísyan ve Umut Ağları. Internet Çağında Toplumsal Hareketler (Ebru Kılıç, Çev.). İstanbul: Koç Üniversitesi Yayınları.

Crampton, R.J. (1997). A concise history of Bulgaria. Cambridge University Press, 36.

Dahan, G. S., \& Levi, E. (2012). Netnografya: Sosyal Mecralarda Tüketici Araştırmaları Üzerine Yeni Bir Metot. Gümüşhane Üniversitesi Illetişim Fakültesi Elektronik Dergisi, 1(3).

Demez, G. (2013). Toplumsal Etkileşim Alanı Olarak Sosyal Medya: Yeni Kapanma ve Özgürleşme Alanları. M. Tuna (Ed.). VII. Ulusal Sosyoloji Kongresi Yeni Toplumsal Yapılanmalar: Geçişler, Kesişmeler, Sapmalar Bildiri Kitabı 1 (s. 435-447). Muğla Sıtkı Koçman Üniversitesi. Erişim Tarihi: 24.03.2021, http://www. sosyolojikongresi.org/s/2498/i/cilt_1.pdf

Durkheim, E. (1912). 1995. The elementary forms of religious life, (Carol Cosman, Trans.). Oxford World's Classics, 1-30.

Doğanay, F. (1996). “Türkiye’ye Göçmen Olarak Gelenlerin Yerleşimi” DPT.YBM 1997, ftp://ftp.dpt.gov. tr/pub/ekutup96

“Facebook kullanıcı sayısı 2,7 milyara ulaştı”. Hürriyet Gazetesi. Erişim tarihi. 17.03.2021.

Hürriyet.com.tr: https://www.hurriyet.com.tr/teknoloji/facebook-kullanici-sayisi-2-7-milyara-ulasti41636653\#: :text=Statista $\% 20$ verilerinden $\% 20$ elde $\% 20$ edilen $\% 20$ bilgilere,say $\% C 4 \% B 1 s \% C 4 \% B 1 \% 20$ 2\%2C7\%20milyar\%20oldu.

Gerbaudo, P. (2013). Twitler ve Sokaklar (Osman Akınhay, Çev.). İstanbul: Agora.

Heilbron, J., \& Sapiro, G. (2007). Outline for a sociology of translation. Current issues and future prospects. Benjamins Translation Library, 74, 93.

Jenkins, H. (2006a). Convergence culture: Where old and new media collide. New York: NYU Press.

Jenkins, J. (2006b). Fans, Bloggers and Gamers. Exploring Participatory Culture, New York: New York University Press. 
Jenkins, H. (2009). Confronting the challenges of participatory culture: Media education for the 21st century. Cambridge: The MIT Press.

Jenkins, H (2019). Cesur Yeni Medya: Teknolojiler ve Hayran Kültürü (Nihal Yeğengil, Çev.). İstanbul: İletişim.

Karakoç, E., Gülsünler, M. E. (2012). Kullanımlar ve doyumlar yaklaşımı bağlamında Facebook: Konya üzerine bir araştırma [Elektronik Sürüm]. Akdeniz Üniversitesi Illetişim Fakültesi Dergisi, 18, ss.42-57.

"Kitlesel Akınlar”. T.C. İçişleri Bakanlığı Göç İşleri İdaresi Genel Müdürlüğü. Erişim Tarihi: 24.03.2021. Goc. gov.tr: https://www.goc.gov.tr/kitlesel-akinlar

Kozinets, R. (2006). "Click to connect: netnography and tribal advertising”, Journal of advertising research içinde, 46 (3), 279-288.

Kozinets, R. (2010). Netnography: Doing Ethnographic Research Online, Sage Publications Ltd., London, 221.

Köseoğlu, Ö. (2013). Sosyal Ağ Sitesi Kullanıcılarının Motivasyonları: Facebook Üzerine Bir Araştırma. Selçuk Illetişim, 7 (2), 58-81. https://dergipark.org.tr/tr/pub/josc/issue/19024/200577

Kurmel, D., \& Görgüler, Z., (2020). Toplumterimbilimsel bir yaklaşım örneği: Ekoloji terimlerinin çevrimiçi ağlarda dolaşımı. RumeliDE Dil ve Edebiyat Araştırmaları Dergisi, no.18, 725-736.

Lévy, P. (1999). Collective Intelligence: Mankind's Emerging World in Cyberspace. Cambridge: Perseus Books.

Özbölük, T., \& Dursun, Y. (2015). Pazarlama Araştırmalarında Paradigmal Dönüşüm ve Etnografinin Dijital Evrimi: Netnografi. Erciyes üniversitesi iktisadi ve idari bilimler fakültesi dergisi, (46), 227-247.

“Преброяване 2011”. [Nüfus Sayımı 2011] НАЦИОНАЛЕН СТАТИСТИЧЕСКИ ИНСТИТУТ. [Ulusal İstatiksel Kurumu]. Erişim Tarihi: 24.03.2021. Nsi.bg: http://www.nsi.bg/sites/default/files/files/pressreleases/ Census2011 final.pdf

Stein, J. (2000). The Politics of National Minority Participation in Post-communist Europe. M.E. Sharpe, 238. ISBN 0-7656-0528-7

Sütlüoğlu, T. (2015). Sosyal paylaşım ağlarında gençlerin sosyalleşme ve kimlik inşası süreçleri: Facebook örneği. Folklor/Edebiyat, 21(83), 125-147.

Turhan, S. (2017). Yeni Medyada Katılımcı Kültür ve Troller: Adana Şehri Üzerine Trollerin Dil Kullanım Pratikleri. AJIT-e: Bilişim Teknolojileri Online Dergisi, 8(30), 305-323.

Zhao, S.; Sherri, G.; Martin, J. (2008). Identity construction on Facebook: Digital empowerment in anchored relationships [Elektronik Sürüm]. Computers in Human Behavior, 24, 1816-1836. http://newsroom.fb.com/ company-info/ Erişim Tarihi: 24.11.2019. 
